\title{
Desempenho dos estudantes de cursos presenciais e a distância no Enade em 2015, 2016 e 2017
}

Angelo Luiz Cortelazzo a Cristina de Carvalho Ares Elisei ${ }^{\mathrm{b}}$

\section{Resumo}

Com o objetivo de comparar o desempenho de concluintes de cursos presenciais e a distância (EaD) nos Exames Nacionais de Desempenho dos Estudantes (Enade) de 2015, 2016 e 2017, foi feita a análise exploratória dos dados disponíveis, verificado o desempenho dos estudantes de todas as turmas participantes e dos concluintes de instituições que ofereceram simultaneamente cursos presenciais e a distância. Os resultados mostraram que estudantes de cursos $\mathrm{EaD}$, especialmente naqueles com grande quantidade de concluintes, tendem a apresentar um conceito Enade contínuo numericamente menor e médias com maior variabilidade. Para uma instituição que oferece cursos $\mathrm{EaD}$ e presenciais, houve diferença nos resultados em função da sua natureza jurídica: escolas públicas tiveram conceitos significativamente maiores nos cursos presenciais, enquanto que nas escolas privadas essa diferença não foi observada ou foi menos evidente. Para os cursos $\mathrm{EaD}$, a despeito de valores numericamente maiores nas instituições públicas, não houve diferença significativa entre os resultados.

Palavras-chave: Educação Superior. Enade. Avaliação. Ensino Presencial. Ensino a Distância.

\section{Introdução}

A Lei de Diretrizes e Bases da Educação Nacional (LDB) determina que compete à União baixar normas gerais para os cursos de graduação e assegurar processos nacionais de avaliação do rendimento escolar e das instituições (art. $9^{\circ}$, VI, VII e VIII), o que é reiterado no caput do art. 46: "A autorização e o reconhecimento de cursos, bem como o credenciamento de instituições de educação superior, terão prazos limitados, sendo renovados, periodicamente, após processo regular de avaliação" (BRASIL, 1996).

\footnotetext{
a Universidade Estadual de Campinas, Campinas, SP, Brasil.

b Centro Paula Souza, Fatec Pindamonhangaba, Pindamonhangaba, SP, Brasil.
} 
Em 2004 foi aprovada a Lei no 10.861 que instituiu o Sistema Nacional de Avaliação da Educação Superior - Sinaes (BRASIL, 2004) e substituiu a sistemática então utilizada (DIAS SOBRINHO, 2010). Nessa Lei, ficaram estabelecidas as três avaliações que formam o Sinaes: a) Avaliação institucional interna e externa (art. $3^{\circ}$ ); b) Avaliação dos cursos de graduação (art. $4^{\circ}$ ) e c) Avaliação dos estudantes (Exame Nacional de Desempenho dos Estudantes -Enade), com periodicidade máxima de três anos (art. $5^{\circ}$ ).

Os objetivos da avaliação dos cursos de graduação são: a) identificar as condições de Ensino oferecidas aos estudantes, em especial as relativas à organização didáticopedagógica, ao corpo social e às instalações físicas; b) verificar a articulação entre Plano de Desenvolvimento Institucional (PDI), Projeto Pedagógico de Curso (PPC), currículo, vocação institucional e inserção regional e c) analisar a aderência às Diretrizes Curriculares Nacionais - DCN (BRASIL, 2004; BRITO, 2008).

Em 2007, foi publicada a Portaria Normativa ${ }^{\circ} 40$, republicada em 2010, alinhando os ciclos de avaliação dos cursos de graduação ao do Enade e, portanto, uma periodicidade trienal (BRASIL, 2010). O Exame já passou por inúmeras alterações visando ao seu aprimoramento, destacando-se sua mudança de amostral para populacional, em 2009, a sua utilização para avaliação dos ingressantes e a prova de conhecimentos gerais e específicos realizada apenas para concluintes, a partir de 2011 (BRITO, 2015).

A Educação Superior brasileira tem tido uma expansão acentuada desde o final do século passado, mas foi a partir de 2005 que os cursos desenvolvidos a distância e previstos na LDB (BRASIL, 1996) tiveram regulamentada a sua oferta (BRASIL, 2005) e, assim, sua expansão passou a ser mais significativa (CAETANO et al., 2015). Dados do Censo da Educação Superior no Portal do Instituto Nacional de Estudos e Pesquisas Educacionais Anísio Teixeira - Inep (2019) indicam que em 2005 havia pouco mais de 110 mil matriculados em cursos superiores desenvolvidos a distância e esse contingente passou para mais de 1,75 milhão em 2017, representando um aumento superior a $1.400 \%$. Em contrapartida, no mesmo período, os cursos presenciais expandiram suas matrículas de 4,5 para 6,5 milhões de alunos, ou 47\% de aumento. Assim, o Ensino a Distância (EaD), que representava 2,5\% dos matriculados em 2005, passou a representar, em 2017, mais de 21\% desse total (INEP, 2019).

A partir de 2015, o Inep passou a divulgar, de forma distinta, os conceitos obtidos no Enade pelos concluintes de cursos presenciais e a distância, completando, em 2017, um ciclo avaliativo para todos os cursos que realizaram esse exame no período. Tal procedimento abriu a possibilidade de comparação entre as duas formas de desenvolvimento de cursos, sem a necessidade de autorizações especiais, conforme vinha sendo feito até aquela data (CAETANO et al., 2015; RODRIGUES et al., 2016). 
Assim, o presente trabalho teve como objetivo fazer um levantamento do desempenho dos estudantes que participaram do Enade em 2015, 2016 e 2017, comparando os resultados obtidos por estudantes concluintes de cursos presenciais e a distância em um ciclo avaliativo completo, visando contribuir para o estabelecimento de um perfil de desempenho para essas modalidades, já que vários trabalhos têm abordado o tema, mas, normalmente, de forma pontual, ou com dados específicos de um único ano de exame, tipo de curso, ou modalidade (BIELSCHOWSKY, 2018a; BITTENCOURT; ROESLER; DIAS, 2015; OLIVEIRA; PICONEZ, 2017).

\section{Metodologia}

A pesquisa realizada caracterizou-se como exploratória, de abordagem quantitativa e com delineamento documental. Foram consultados os resultados dos Enade de 2015, 2016 e 2017, cujas tabelas incluíram a modalidade de desenvolvimento dos cursos participantes. Os arquivos usados foram aqueles disponibilizados no site do Inep, a saber: Enade 2015, com dados atualizados em 03/10/2017; Enade 2016, com dados atualizados em 06/09/2017 e Enade 2017 (INEP, 2018).

A análise foi feita no conjunto total de cursos, separados nas duas modalidades de desenvolvimento: presencial ou a distância. Foram também listadas as quantidades de concluintes inscritos e de participantes das provas, assim como os cursos que não obtiveram conceito Enade e as diferentes performances com relação aos conceitos 1 a 5 obtidos pelos concluintes.

Os dados referentes à quantidade de concluintes por Instituições de Educação Superior (IES), nas duas modalidades e em cada ano do exame, foram submetidos a uma análise exploratória, para a obtenção do diagrama de Tukey, com a determinação dos respectivos quartis, mediana, valores que se inserem em uma curva de distribuição normal, valores soltos e valores desgarrados (TUKEY, 1977).

Em seguida, foram calculadas as quantidades, as médias ponderadas e as aritméticas de cada grupo de concluintes participantes dos exames, em cada quartil de distribuição. Para o quartil superior, contendo os cursos com quantidades classificadas como pontos desgarrados na análise exploratória, foram calculados separadamente os cursos pertencentes à distribuição normal ( $4^{\circ}$ quartil $\left.\mathrm{A}\right) \mathrm{e}$ aqueles contendo esses valores desgarrados ( $4^{\circ}$ quartil B).

Para a comparação entre os resultados obtidos apenas para as IES que participaram do exame com algum curso desenvolvido a distância, foram agrupadas todas as IES nessa condição e calculadas as médias dos conceitos Enade contínuo para cada modalidade oferecida pela respectiva IES. 
Finalmente, foi realizado o Teste T para comparação entre as médias obtidas em cada ano e em cada modalidade de curso, com nível de significância de 95\% $(\mathrm{p}=0,05)$ (LAPPONI, 2005), a fim de estabelecer possíveis diferenças entre os conceitos obtidos pelos egressos dos cursos presenciais ou a distância em cada instituição participante dos exames analisados.

\section{Resultados}

Em 2015, foram avaliados cursos de bacharelado e de tecnologia da área de gestão e de turismo; em 2016, os bacharelados e os cursos superiores de tecnologia da área da saúde e do meio ambiente e, finalmente, em 2017, foram avaliados cursos de bacharelado e de tecnologia da área de ciências sociais, de exatas e de engenharia, além dos cursos de licenciatura. A quantidade de cursos, de número de concluintes inscritos e de participantes encontra-se descrita na Tabela 1.

Percebe-se que os cursos a distância representam apenas cerca de 5\% do total de cursos avaliados, mas atingiram, em 2017, 27\% dos inscritos, o que mostra que eles apresentaram uma maior quantidade de concluintes por curso. Em termos de participação, houve um decréscimo do percentual de concluintes EaD em relação aos inscritos em todos os exames, mostrando que o percentual de abstenção dos cursos $\mathrm{EaD}$ foi superior àquele dos cursos presenciais. No triênio, mais de 1 milhão de estudantes inscreveram-se e participaram do Exame (Tabela 1).

A quantidade de cursos participantes também foi bastante variável no período e no decorrer das áreas abrangidas em cada ano do ciclo: no Enade de 2015, basicamente os cursos de administração e de gestão, incluídos os cursos superiores de tecnologia. Nesse grupo, os bacharelados em administração e em ciências contábeis e o Curso Superior de Tecnologia (CST) em gestão de recursos humanos contribuíram com os maiores contingentes de inscritos, tanto nos cursos presenciais quanto no EaD e representaram quase metade do total de inscritos. Em 2016, a área da saúde e do meio ambiente teve uma quantidade de cursos sensivelmente menor no país, e os de maior quantidade de inscritos - Enfermagem, Educação Física e Serviço Social -, com baixa quantidade de concluintes $\mathrm{EaD}$ nos dois primeiros, assim como na maioria dos demais, levando a um percentual de apenas 1,2\% (51 cursos) em relação ao total de 4.300. Finalmente, em 2017, houve uma grande concentração de egressos de cursos presenciais de engenharia, especialmente de engenharia civil e de produção e, nos cursos a distância, os destaques vão para os cursos superiores de tecnologia, em especial, análise e desenvolvimento de sistemas e licenciatura, com destaque para pedagogia. Naquele ano, o Enade contou com mais de 10 mil diferentes cursos inscritos, dos quais 5,1\% deles desenvolvidos a distância. 


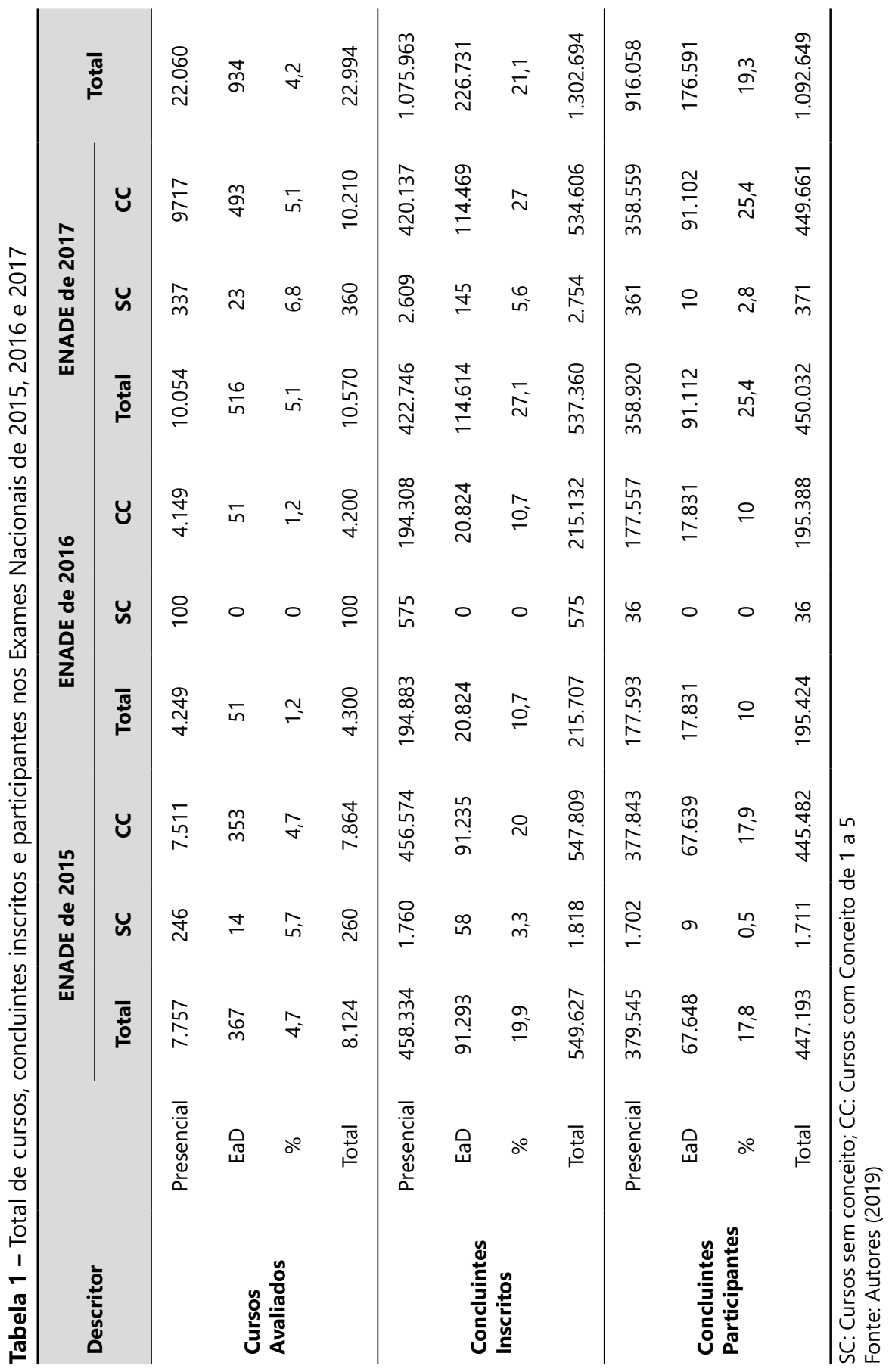


Em todas as edições do exame houve um percentual da ordem de 2 a $3 \%$ dos cursos que não obtiveram conceito (SC), seja por ter havido a inscrição ou a participação de um único candidato, seja por não ter havido concluinte participante do exame, como dois dos motivos mais importantes. Também ocorreram alguns casos em que houve a apuração de algum problema de aplicação ou outro motivo de irregularidade, sempre devidamente apurado. No período, o contingente de alunos concluintes que se encontrava nos cursos "SC" foi sempre inferior a $1 \%$ do total de participantes e, na maior parte dos casos, 0,1 a $0,3 \%$ desse total (Tabela 1 ).

A quantidade de cursos participantes e os conceitos obtidos para a faixa Enade (de 1 a 5) está listada na Tabela 2, na qual também são mostrados os percentuais de cada conceito no total de cursos participantes.

Tabela 2 - Quantidade de cursos participantes do Enade de 2015, 2016 e 2017, conforme conceito obtido e respectivos percentuais

\begin{tabular}{|c|c|c|c|c|c|c|c|}
\hline Concei & & 1 & 2 & 3 & 4 & 5 & Total \\
\hline \multirow{4}{*}{2015} & Presencial & 264 & 2.097 & 3.308 & 1.452 & 390 & 7.511 \\
\hline & $\%$ & 3,5 & 27,9 & 44 & 19,3 & 5,2 & 100 \\
\hline & Distância & 9 & 89 & 164 & 77 & 14 & 353 \\
\hline & $\%$ & 2,5 & 25,2 & 46,5 & 21,8 & 4 & 100 \\
\hline \multirow{4}{*}{2016} & Presencial & 167 & 982 & 1.683 & 1.053 & 264 & 4.149 \\
\hline & $\%$ & 4 & 23,7 & 40,6 & 25,4 & 6,4 & 100 \\
\hline & Distância & 3 & 25 & 16 & 5 & 2 & 51 \\
\hline & $\%$ & 5,9 & 49 & 31,4 & 9,8 & 3,9 & 100 \\
\hline \multirow{4}{*}{2017} & Presencial & 477 & 2.678 & 3.801 & 2.173 & 588 & 9.717 \\
\hline & $\%$ & 4,9 & 27,6 & 39,1 & 22,4 & 6,1 & 100 \\
\hline & Distância & 31 & 194 & 195 & 61 & 12 & 493 \\
\hline & $\%$ & 6,3 & 39,4 & 39,6 & 12,4 & 2,4 & 100 \\
\hline
\end{tabular}

Fonte: Autores (2019)

Como as duas populações de curso eram muito diferentes, optou-se pela abordagem percentual. Então, foi utilizada a soma dos percentuais de cada modalidade em um dado conceito e restabelecido o percentual de cada uma naquele conceito (Figura 1). 
Figura 1 - Percentual da participação dos cursos presenciais e a distância em cada conceito, no período analisado

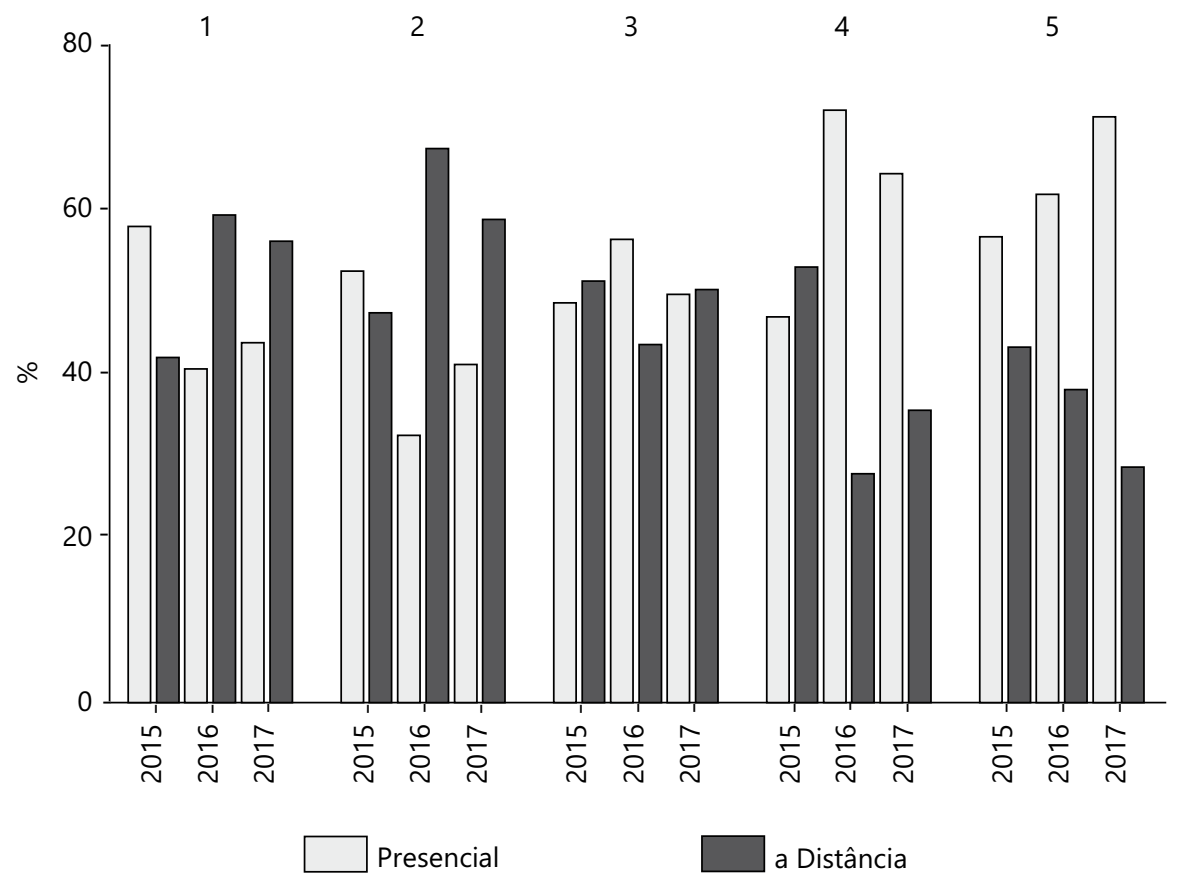

Fonte: Autores (2019)

Percebe-se que os cursos presenciais apresentaram os maiores percentuais de notas 4 e 5 em todos os anos, à exceção de nota 4 em 2015, quando os valores foram próximos a 50\%. Do mesmo modo, em 2016 e em 2017, os cursos a distância tiveram maiores percentuais de notas 1 e 2 quando comparados aos presenciais. Finalmente, as notas 3 oscilaram pouco e de forma aleatória, mantendo-se em torno dos $50 \%$ em todos os anos (Figura 1).

Como os conceitos são decorrentes da quantidade de alunos presentes nas provas, foram utilizados esses valores para uma análise exploratória dos participantes dos exames, não considerados aqueles em que os cursos não lograram nenhum conceito Enade (faixa). Os valores da mediana (MD), quartil inferior (J1), quartil superior (J2), bem como o número de cursos $(\mathrm{N})$ e o menor e o maior valor de participantes do curso de uma dada instituição (*) encontram-se dispostos no Diagrama de Tukey apresentado na Figura 2. 
Figura 2 - Diagrama esquemático de Tukey para as quantidades de alunos que participaram do Enade em 2015, 2016 e 2017

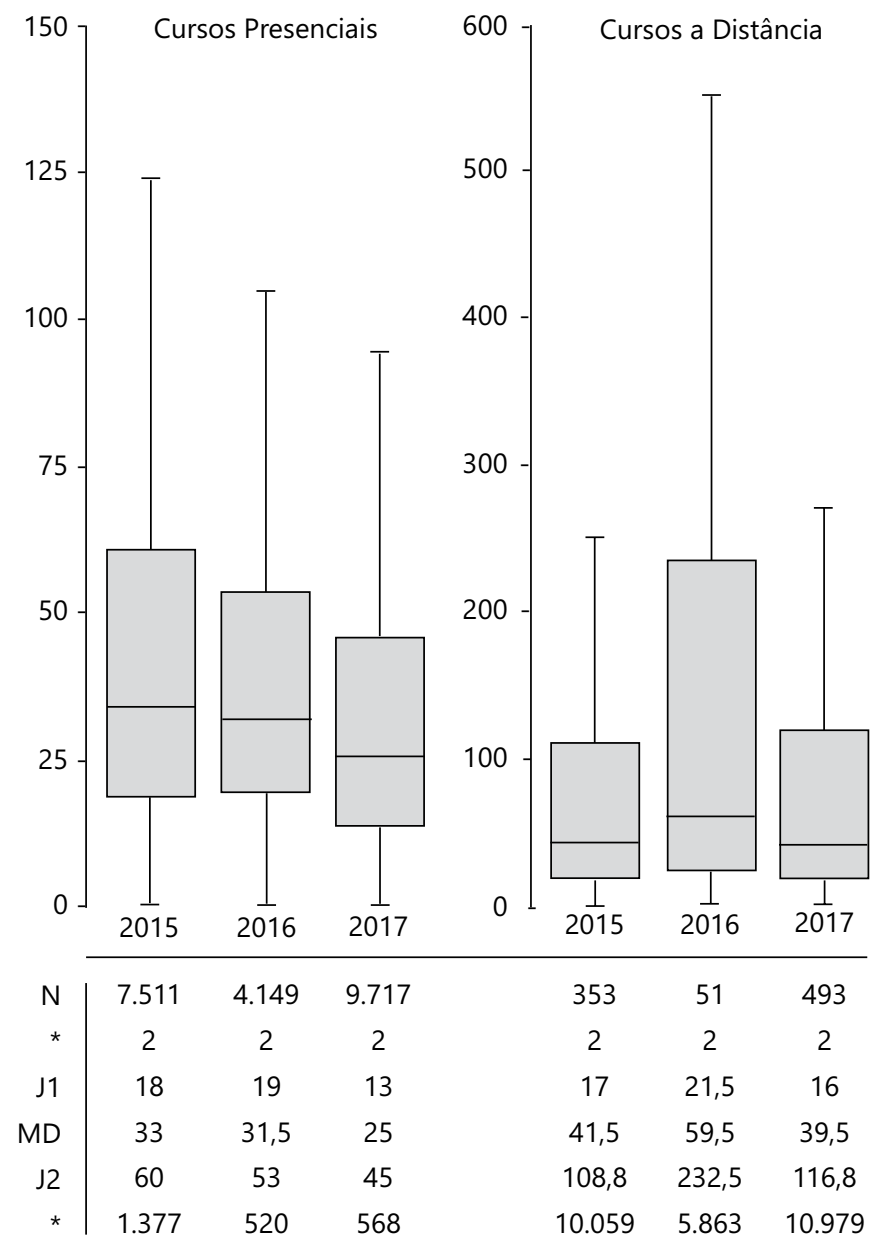

Fonte: Autores (2019)

Em todos os anos e modalidades, a porção da amostra que representava $50 \%$ da população de alunos que participaram do exame teve sua parte inferior menor, significando que houve uma concentração maior de turmas de concluintes de uma IES com um número inferior de participantes com relação à mediana. Do mesmo modo, houve uma maior dispersão acima da mediana e, em todos os casos, houve pontos desgarrados da amostra populacional normal, que são aqueles valores superiores aos limites estabelecidos por 1,5 vez o valor do intervalo interquartílico 
(J1 a J2) somado ao quartil superior, ou subtraído do inferior (TUKEY, 1977). Assim, a alta quantidade de cursos com baixos valores de participantes fez com que se atingisse o valor zero para todos os anos de exame e de modalidades, portanto, nenhum valor desgarrado. Já para os valores acima do $3^{\circ}$ quartil, uma quantidade considerável de pontos desgarrados foi obtida, mostrando que houve um pequeno número de cursos com valores muito elevados de participantes e que fugiram do esperado para uma distribuição normal, tanto nos cursos presenciais quanto nos a distância (Tabela 3).

Tabela 3 - Quantidade de pontos desgarrados em cada ano e modalidade de curso analisados

\begin{tabular}{lccccc}
\hline Ano & Modalidade & Amostra & Desgarrados & $\%$ & UV/MD ${ }^{1}$ \\
\hline \multirow{2}{*}{$\mathbf{2 0 1 5}$} & Presencial & 7.511 & 541 & 7,2 & 41,7 \\
& a Distância & 353 & 43 & 12,2 & 242,4 \\
\hline \multirow{2}{*}{$\mathbf{2 0 1 6}$} & Presencial & 4.149 & 263 & 6,3 & 16,5 \\
& a Distância & 51 & 6 & 11,8 & 98,5 \\
\hline \multirow{2}{*}{$\mathbf{2 0 1 7}$} & Presencial & 9.717 & 689 & 7,1 & 22,7 \\
& a Distância & 493 & 56 & 11,4 & 277,9 \\
\hline
\end{tabular}

${ }^{1}$ Quantidade de vezes que o curso com maior número de inscritos é maior do que a mediana Fonte: Autores (2019)

Percebe-se que não apenas os cursos a distância tiveram um percentual maior de pontos desgarrados relativamente àqueles desenvolvidos presencialmente, como também apresentaram uma nítida variação maior do número de inscritos em relação à mediana dos cursos, confirmando uma população amostral muito mais heterogênea no que tange à quantidade de participantes de cada curso analisado pelo exame. Esses valores foram superiores a 240 vezes em 2015 e em 2017 e quase 100 vezes em 2016. Para os cursos presenciais, os valores oscilaram entre cerca de 20 a 40 vezes (Tabela 3). Dados apresentados por Bielschowsky (2018a) mostram que, em 2016, cinco instituições que ofertavam cursos a distância detinham $58 \%$ dos matriculados dessa modalidade.

Os valores obtidos no presente trabalho referem-se ao total de alunos concluintes de um dado curso e instituição e, obviamente, devem representar a somatória de diferentes turmas presenciais ou de polos de apoio presencial existentes naquele curso. Desse modo, essa quantidade maior não deveria interferir de maneira significativa no desempenho dos concluintes dos cursos, já que eles se originaram da somatória de grupos com quantidades de alunos mais próxima das outras IES. 
Entretanto, essa maior heterogeneidade no $4^{\circ}$ quartil foi detalhada de modo a verificar se ela influenciou no desempenho dos cursos nessas condições.

A análise dos inscritos, presentes, e os cálculos dos conceitos após ponderação ou a partir da média aritmética para cada quartil da população do Enade 2015 estão apresentados na Tabela 4 , que também subdivide o $4^{\circ}$ quartil em duas partes: $4^{\circ}$ Quartil $\mathrm{A}$, que representa o número de concluintes com valores pertencentes à distribuição normal da população determinada pelo diagrama de Tukey; $4^{\circ}$ Quartil $\mathrm{B}$, contendo IES com um total de concluintes maior e que foram considerados pontos desgarrados na análise exploratória, já que apresentaram valores superiores a 1,5 X a diferença interquartílica, conforme explicitado anteriormente (Tabela 4).

Tabela 4 - Quantidade de cursos participantes, inscritos e presentes no Enade 2015 e seu desempenho em cada quartil da população analisada

\begin{tabular}{|c|c|c|c|c|c|c|c|}
\hline 2015 & Curso & $1^{\circ}$ Quartil & $2^{\circ}$ Quartil & $3^{\circ}$ Quartil & $4^{\circ}$ Quartil & $4^{\circ}$ Quartil A & $4^{\circ}$ Quartil B \\
\hline \multirow{7}{*}{ 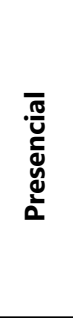 } & Cursos & 1.758 & 1.921 & 1.958 & 1.874 & 1.333 & 541 \\
\hline & Inscritos & 24.637 & 57.781 & 103.934 & 270.280 & 133.548 & 136.732 \\
\hline & Presentes & 18.475 & 47.487 & 86.734 & 226.400 & 111.559 & 114.841 \\
\hline & \% Presentes & 75 & 82,2 & 83,5 & 83,8 & 83,5 & 84 \\
\hline & Conceito (Mp) ${ }^{1}$ & $2,42 \pm 1,41$ & $2,40 \pm 0,92$ & $2,39 \pm 0,94$ & $2,39 \pm 2,15$ & $2,34 \pm 0,97$ & $2,44 \pm 1,79$ \\
\hline & Conceito $(\mathrm{Mp})^{2}$ & $2,42 \pm 0,99$ & $2,40 \pm 0,83$ & $2,40 \pm 0,82$ & $2,37 \pm 0,83$ & $2,35 \pm 0,83$ & $2,42 \pm 0,84$ \\
\hline & Inscritos/curso & 2 a 17 & 18 a 32 & 33 a 60 & 61 a 1.377 & 60 a 123 & 124 a 1.377 \\
\hline \multirow{7}{*}{ 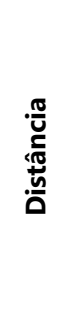 } & Cursos & 85 & 91 & 89 & 88 & 45 & 43 \\
\hline & Inscritos & 1.032 & 3.578 & 8.905 & 77.720 & 9.508 & 68.212 \\
\hline & Presentes & 693 & 2.561 & 6.270 & 58.115 & 7.397 & 50.718 \\
\hline & $\%$ Presentes & 67,2 & 71,6 & 70,4 & 74,8 & 77,8 & 74,4 \\
\hline & Conceito (Mp) ${ }^{1}$ & $2,52 \pm 1,57$ & $2,51 \pm 0,90$ & $2,33 \pm 0,93$ & $1,75 \pm 2,80$ & $2,48 \pm 0,96$ & $1,64 \pm 2,04$ \\
\hline & Conceito $(\mathrm{Mp})^{2}$ & $2,56 \pm 0,97$ & $2,56 \pm 0,76$ & $2,34 \pm 0,71$ & $2,18 \pm 0,72$ & $2,45 \pm 0,71$ & $1,90 \pm 0,61$ \\
\hline & Inscritos/curso & 2 a 16 & 17 a 41 & 42 a 109 & 114 a 10.059 & 14 a 246 & 273 a 10.059 \\
\hline
\end{tabular}

1.Mp: Média ponderada; ${ }^{2}$ Ma: Média Aritmética

Fonte: Autores (2019)

Percebe-se que o $4^{\circ}$ quartil, apesar de representar $25 \%$ dos cursos, apresentou 2,6 vezes mais inscritos que no $3^{\circ}$ quartil, distribuídos de forma equitativa entre as duas subpopulações (A e B). Nos cursos a distância, o $4^{\circ}$ quartil apresentou 8,7 vezes mais inscritos, dos quais, a grande concentração encontra-se na subpopulação B (7,6 vezes), confirmando a presença de cursos com muitos alunos nessa porção da população que realizou o exame (Tabela 4). 
Os resultados mostraram um desempenho mais homogêneo dos alunos de cursos presenciais, independentemente do tamanho das turmas de concluintes participantes, com médias ponderadas oscilando entre 2,39 e 2,42 (Coeficiente de Variação [CV] de $0,5 \%$ ). Para os cursos $\mathrm{EaD}$, esses conceitos variaram de 2,52 a 1,75 e tiveram uma tendência à diminuição à medida em que as turmas aumentaram $(\mathrm{CV}=13,8 \%)$. Ao serem isolados os pontos desgarrados, os cursos presenciais tiveram médias entre 2,42 e 2,34 (CV = 1,2\%) mostrando que, para essa população, o desempenho dos alunos originários de cursos com maior número de concluintes foi igual ao das demais turmas. Já nos cursos a distância, os coeficientes médios variaram de 2,52 a $2,33(\mathrm{CV}=3,1 \%)$ e mostraram a influência dos pontos desgarrados na diminuição do conceito médio de desempenho e no aumento do coeficiente de variação. Tal característica sinalizou um efeito negativo provocado pelo aumento do número de inscritos de um dado curso e instituição, no desempenho médio dos alunos no Enade para os cursos da modalidade a distância. Essa constatação foi reforçada, em 2015, pelo fato do conceito ponderado dos cursos $\mathrm{EaD}$ ter valores numericamente superiores nos dois primeiros quartis (até o tamanho correspondente à mediana) e inferior nos dois outros. Entretanto, a faixa de valores, próximos a 2,3-2,5, foi a mesma para os cursos presenciais ou a distância naquele ano do exame nacional.

As médias aritméticas apresentaram variações menores, como esperado, principalmente quando o número de concluintes participantes por turma variou numericamente de forma mais significativa ( $4^{\circ}$ quartil), o que não foi registrado nessas médias. Entretanto, os valores das duas médias até o $3^{\circ}$ quartil foi muito semelhante, mostrando uma maior homogeneidade no número de alunos por curso e um desempenho similar nesse intervalo. Efetivamente, para os cursos presenciais, os dois quartis próximos da mediana e que continham metade da população $\left(2^{\circ}\right.$ e $\left.3^{\circ}\right)$ apresentaram um número mínimo e máximo de alunos em cada intervalo que foi menor do que o dobro $\left(18\right.$ a 32 no $2^{\circ} \mathrm{Q}$ e 33 a 60 no $\left.3^{\circ}\right)$. Para EaD, esses valores variaram um pouco mais (de 17 a 41 e de 42 a 109), mas não de forma muito diferente daquela apresentada pela modalidade presencial.

Com relação ao tamanho dos quartis, o critério foi utilizar os valores da análise exploratória (Figura 2), mas incorporar aos quartis próximos à mediana todas as turmas de IES com o mesmo número de alunos participantes e subtraí-lo do $1^{\circ}$ ou do $4^{\circ}$ quartis, já que seria difícil considerar turmas do mesmo tamanho em quartis diferentes.

Conforme já salientado, em 2016 houve a participação de um número menor de cursos no exame, decorrente da menor quantidade de oferta na área da saúde e do meio ambiente analisadas naquele ano do ciclo avaliativo. Além disso, a área foi representada por carreiras em que o desenvolvimento a distância foi menor, justificando haver apenas 51 diferentes cursos $\mathrm{EaD}$ participantes do exame daquele ano (Tabela 5). 
Tabela 5 - Quantidade de cursos, inscritos e presentes no Enade 2016 e seu desempenho em cada quartil da população analisada

\begin{tabular}{|c|c|c|c|c|c|c|c|}
\hline 2016 & Curso & $1^{\circ}$ Quartil & $2^{\circ}$ Quartil & $3^{\circ}$ Quartil & $4^{\circ}$ Quartil & $4^{\circ}$ Quartil A & $4^{\circ}$ Quartil B \\
\hline \multirow{7}{*}{ 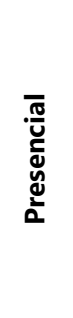 } & Cursos & 1.017 & 1.057 & 1.038 & 1.037 & 774 & 263 \\
\hline & Inscritos & 13.377 & 28.749 & 46.407 & 105.775 & 61.371 & 44.404 \\
\hline & Presentes & 11.716 & 26.383 & 42.608 & 96.850 & 56.487 & 40.363 \\
\hline & $\%$ Presentes & 87,6 & 91,8 & 91,8 & 91,6 & 92 & 90,9 \\
\hline & Conceito (Mp) ${ }^{1}$ & $2,54 \pm 1,40$ & $2,53 \pm 0,97$ & $2,57 \pm 0,99$ & $2,35 \pm 1,41$ & $2,42 \pm 0,99$ & $2,25 \pm 1,16$ \\
\hline & Conceito $(\mathrm{Mp})^{2}$ & $2,55 \pm 1,02$ & $2,52 \pm 0,87$ & $2,57 \pm 0,89$ & $2,39 \pm 0,88$ & $2,43 \pm 0,89$ & $2,28 \pm 0,85$ \\
\hline & Inscritos/curso & 2 a 18 & 19 a 31 & 32 a 53 & 54 a 520 & 54 a 104 & 105 a 520 \\
\hline \multirow{7}{*}{ 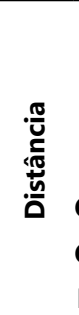 } & Cursos & 13 & 13 & 13 & 12 & 6 & 6 \\
\hline & Inscritos & 285 & 780 & 2.108 & 17.651 & 2.513 & 15.138 \\
\hline & Presentes & 143 & 561 & 1.799 & 15.328 & 2.040 & 13.288 \\
\hline & $\%$ Presentes & 50,2 & 71,9 & 85,3 & 86,8 & 81,2 & 87,8 \\
\hline & Conceito (Mp) ${ }^{1}$ & $2,08 \pm 1,00$ & $2,03 \pm 0,72$ & $2,06 \pm 1,29$ & $1,46 \pm 1,59$ & $1,47 \pm 0,30$ & $1,45 \pm 0,96$ \\
\hline & Conceito $(\mathrm{Mp})^{2}$ & $2,32 \pm 0,90$ & $2,03 \pm 0,60$ & $2,03 \pm 0,84$ & $1,51 \pm 0,33$ & $1,48 \pm 0,26$ & $1,54 \pm 0,39$ \\
\hline & Inscritos/curso & 2 a 22 & 30 a 64 & 67 a 261 & 303 a 5.863 & 303 a 442 & 788 a 5.863 \\
\hline
\end{tabular}

${ }^{1} \mathrm{Mp}$ : Média ponderada; ${ }^{2} \mathrm{Ma:}$ Média Aritmética

Fonte: Autores (2019)

Para a área da saúde e do meio ambiente, observou-se a mesma característica já apontada no Enade 2015: $4^{\circ}$ quartil com um número de inscritos muito superior, especialmente na subpopulação B dos cursos desenvolvidos a distância. Os conceitos obtidos em cada quartil também foram da mesma ordem, com médias oscilando entre 2,57 e 2,35 para os cursos presenciais $(\mathrm{CV}=3,5 \%)$, enquanto que os cursos a distância oscilaram entre 2,08 e 1,46, um pouco menores, portanto, no $4^{\circ}$ quartil. Os concluintes de $\mathrm{EaD}$ apresentaram a tendência igual à diminuição apresentada no ano anterior e também um CV elevado e igual a 13,6\%. Ao serem isolados do cálculo os pontos desgarrados, percebeu-se uma oscilação entre 2,57 e 2,42 ( $\mathrm{CV}=2,2 \%)$, mas no desempenho dos concluintes da modalidade a distância, a oscilação foi praticamente a mesma, de 2,08 a 1,47 (CV =13,3\%).

Para os cursos desenvolvidos a distância, houve uma diminuição do desempenho de todo o conjunto de alunos do $4^{\circ}$ quartil e não apenas de seus pontos desgarrados. Cabe destacar que no ano de 2016, apenas 51 cursos desenvolvidos a distância participaram do Exame e a natureza dos cursos da área, especialmente da saúde, pode contribuir para esse comportamento, já que nesse caso, estágios e atividades práticas desenvolveram-se em ambientes mais específicos e que dependeram da presença de equipamentos e, principalmente, de profissionais em quantidade 
suficiente para possibilitar que os estudantes desempenhassem, de forma efetiva, as atividades que poderiam consolidar os conhecimentos tratados ao longo dos cursos, o que pode ser dificultado quando o número de polos de apoio presencial aumenta. Essa explicação pode ser reforçada pelo fato de que, em 2016, também os pontos desgarrados dos cursos presenciais terem tido uma queda mais acentuada com relação ao outro grupo do $4^{\circ}$ quartil.

Finalmente, na Tabela 6 são apresentados os resultados do Enade de 2017, onde pode-se observar comportamento semelhante àquele dos anos anteriores.

Tabela 6 - Quantidade de cursos, inscritos e presentes no Enade 2017 e seu desempenho em cada quartil da população analisada

\begin{tabular}{|c|c|c|c|c|c|c|c|}
\hline 2017 & Curso & $1^{\circ}$ Quartil & $2^{\circ}$ Quartil & $3^{\circ}$ Quartil & $4^{\circ}$ Quartil & $4^{\circ}$ Quartil A & $4^{\circ}$ Quartil B \\
\hline \multirow{7}{*}{ 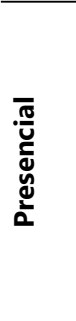 } & Cursos & 2.253 & 2.552 & 2521 & 2.391 & 1.702 & 689 \\
\hline & Inscritos & 22.305 & 54.807 & 99.113 & 243.912 & 125.079 & 118.833 \\
\hline & Presentes & 17.021 & 46.089 & 84.399 & 211.050 & 107.642 & 103.408 \\
\hline & $\%$ Presentes & 76,3 & 84,1 & 85,2 & 86,5 & 86,1 & 87 \\
\hline & Conceito (Mp) ${ }^{1}$ & $2,42 \pm 1,42$ & $2,40 \pm 1,02$ & $2,42 \pm 0,99$ & $2,38 \pm 1,69$ & $2,42 \pm 1,06$ & $2,35 \pm 1,31$ \\
\hline & Conceito $(\mathrm{Mp})^{2}$ & $2,44 \pm 1,06$ & $2,40 \pm 0,89$ & $2,41 \pm 0,87$ & $2,41 \pm 0,91$ & $2,42 \pm 0,91$ & $2,38 \pm 0,93$ \\
\hline & Inscritos/curso & 2 a 12 & 13 a 24 & 25 a 45 & 46 a 568 & 46 a 93 & 94 a 568 \\
\hline \multirow{7}{*}{$\begin{array}{l}\frac{\pi}{U} \\
\frac{c}{\pi} \\
\frac{\pi}{\pi} \\
\frac{n}{0}\end{array}$} & Cursos & 122 & 124 & 123 & 123 & 67 & 56 \\
\hline & Inscritos & 1.504 & 4.546 & 11.898 & 96.477 & 15.321 & 81.156 \\
\hline & Presentes & 1.019 & 3.192 & 8.917 & 77.934 & 12.019 & 65.915 \\
\hline & $\%$ Presentes & 67,8 & 70,2 & 74,9 & 80,8 & 78,4 & 81,2 \\
\hline & Conceito (Mp) ${ }^{1}$ & $2,15 \pm 1,37$ & $2,14 \pm 0,99$ & $1,95 \pm 0,92$ & $1,87 \pm 4,21$ & $2,14 \pm 0,68$ & $1,82 \pm 3,18$ \\
\hline & Conceito $(\mathrm{Mp})^{2}$ & $2,20 \pm 1,00$ & $2,14 \pm 0,75$ & $1,98 \pm 0,77$ & $2,08 \pm 0,70$ & $2,19 \pm 0,68$ & $1,95 \pm 0,71$ \\
\hline & Inscritos/curso & 2 a 15 & 16 a 39 & 40 a 117 & 118 a 10.979 & 118 a 267 & 274 a 10.979 \\
\hline
\end{tabular}

${ }^{1} \mathrm{Mp}$ : Média ponderada; ${ }^{2} \mathrm{Ma}:$ Média Aritmética

Fonte: Autores (2019)

Em 2017, as médias dos conceitos ponderados dos cursos EaD também foram numericamente inferiores àquelas obtidas pelos presenciais. Nesses últimos, $\mathrm{o}$ desempenho médio dos concluintes oscilou de 2,42 a 2,38 (CV =0,6\%) e, ao serem retirados os cursos com quantidade de concluintes considerada como ponto desgarrado, as médias foram praticamente as mesmas, variando de 2,42 para 2,40 (CV=0,4\%). Nos cursos da modalidade a distância, as médias tiveram uma variação entre 2,15 e 1,87 (CV $=6 \%$ ) e de 2,15 a 1,95 , quando não considerados os pontos desgarrados ( $\mathrm{CV}=4 \%$ ), que foram os responsáveis pelo menor valor do $4^{\circ}$ quartil como um todo (Tabela 6). 
No Enade 2017, a média dos conceitos em cada quartil pôde ser considerada constante para os dois grupos de cursos, desde que retirada a população de pontos desgarrados, que contribuiu para a diminuição do desempenho nesse quartil, principalmente nos cursos a distância. Também naquele ano, a quantidade de inscritos e de participantes do Enade na subpopulação B do $4^{\circ}$ quartil foi proporcionalmente muito superior àquela dos cursos presenciais, confirmando essa característica dos cursos EaD.

Ainda com relação às Tabelas 4 a 6 , percebe-se que o valor das médias ponderadas dos conceitos permaneceu com uma variação menor nas turmas com um tamanho mais próximo à mediana (menor desvio padrão) ou, em outras palavras, turmas muito pequenas ou muito grandes têm resultados com maior variabilidade de desempenho entre os cursos. Tal variabilidade pode ser decorrente do fato de que naquelas com poucos concluintes, a participação individual teve seu peso aumentado e, com isso, os resultados ficaram mais sujeitos à presença de alunos diferenciados que, no conjunto, tiveram maior influência do que nas turmas maiores, seja em desempenhos excelentes, seja o contrário. No caso do aumento excessivo do número de concluintes, ocorreu o oposto: possíveis alunos mais bem preparados se diluíram no total dos estudantes participantes e, mais do que isso, todos os resultados apontaram para um menor desempenho de turmas grandes, o que é menos significativo nos cursos presenciais, já que a distribuição dos alunos ocorre em diferentes salas de aula de um mesmo campus. Nos cursos desenvolvidos a distância, o aumento de polos de apoio presencial pode levar a maiores diferenças na qualidade das instalações, dos mediadores ou dos tutores presenciais e outros fatores já reportados por Rodrigues et al. (2016) em ciências contábeis e que deverão ser motivo de estudos mais detalhados para confirmação nas demais áreas.

$\mathrm{O}$ fato de termos sempre uma quantidade desproporcionalmente maior de inscritos e de participantes do Enade na subpopulação B do $4^{\circ}$ quartil, sempre superior a 7 vezes o valor do $3^{\circ}$ quartil, confirma que há poucos cursos com muitos alunos nessa modalidade e reforçam os dados obtidos por Bielschowsky (2018a; 2018b). O autor verificou que, em 2015 e em 2016, as 5 IES que detinham 58\% das matrículas $\mathrm{EaD}$ no Ensino Superior obtiveram um conceito Enade inferior às 96 outras, que representavam $42 \%$ dos matriculados. Os valores obtidos pelo autor foram de 1,64 (2015) e 1,35 (2016) para as primeiras, e de 2,38 e 2,08 para as demais. Tais valores também estão em conformidade com aqueles obtidos no presente trabalho.

A fim de comparar os desempenhos obtidos pelos cursos de uma dada instituição, foram selecionadas apenas as IES que tiveram a participação de um ou de mais cursos presenciais e a distância, no Enade correspondente. Para cada instituição 
nessa condição, subtraiu-se o conceito médio ponderado obtido pelos seus cursos $\mathrm{EaD}$ daquele obtido pelos seus cursos presenciais. Desse modo, a diferença obtida foi positiva quando o conceito dos cursos presenciais tinha um valor maior, e foi negativa quando o conceito dos cursos a distância tinha um valor maior. Não houve nenhum caso em que os dois conceitos foram numericamente iguais. Os resultados obtidos para os 3 exames analisados encontram-se na Figura 3.

Figura 3 - Diferença entre o conceito obtido por concluintes de cursos presenciais e de cursos a distância em uma mesma IES no Enade 2015, 2016 e 2017
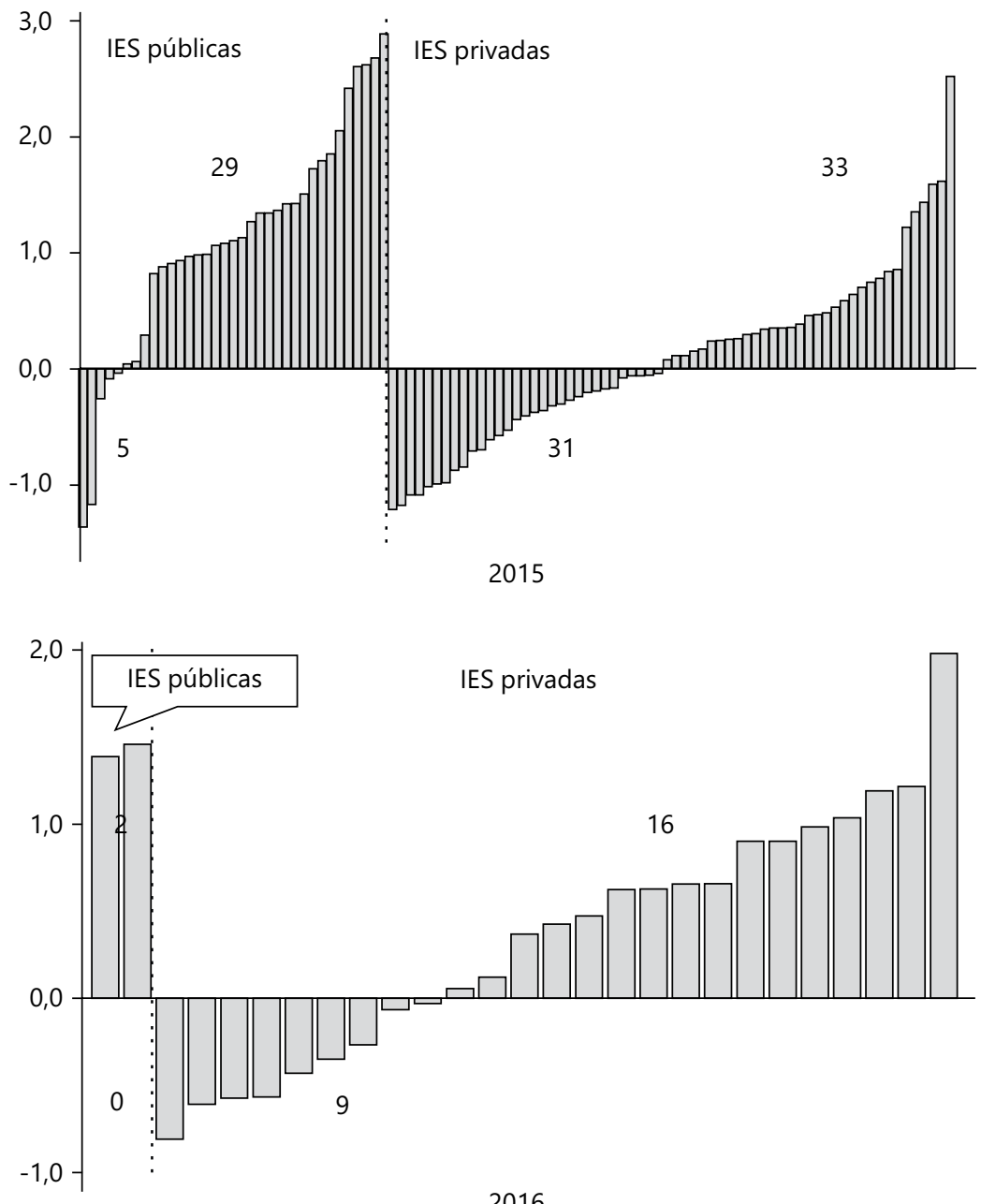

2016

Continua 
Continuação

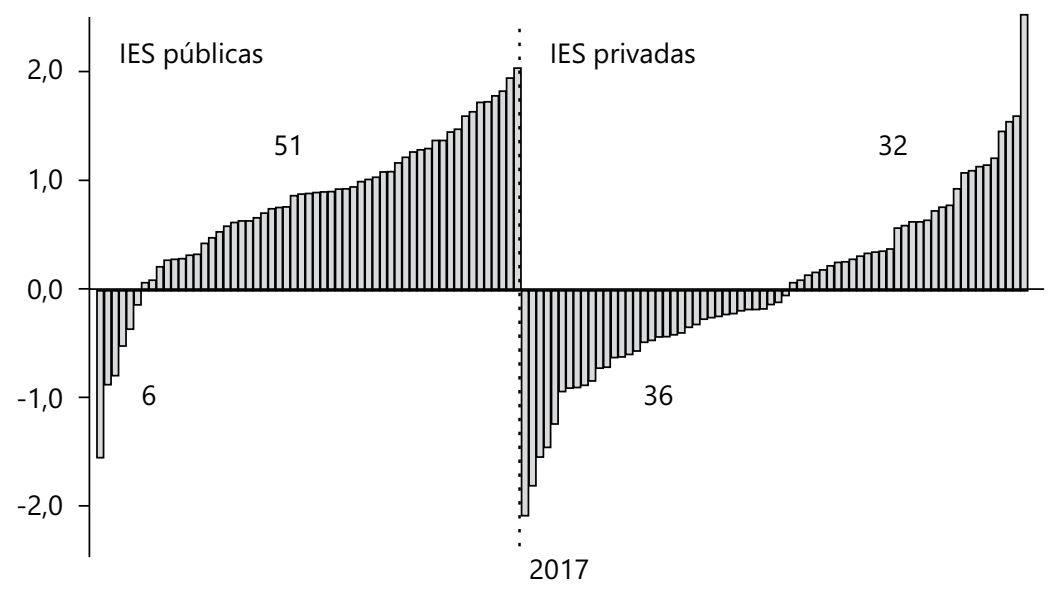

Fonte: Autores (2019)

Dados do Enade 2015 mostram que 100 instituições participaram do exame com concluintes originários de cursos a distância. Delas, houve a participação de 2 Faculdades privadas apenas com concluintes de cursos EaD, com conceitos 2,37 e 2,80 (Conceito Enade faixa 3). As 98 outras, participaram com pelo menos um curso de cada modalidade e as médias ponderadas dos conceitos obtidos revelaram uma diferença de comportamento entre concluintes de IES públicas e privadas, conforme mostrado na Figura 3. Das 34 IES públicas participantes, 29 delas apresentaram conceito Enade contínuo maior nos seus cursos presenciais, quando comparados àqueles ofertados a distância e, em consequência, 5 IES com cursos EaD de melhor desempenho numérico, Nas IES privadas, com 68 participantes, 33 tiveram conceito maior e 31, um conceito Enade menor.

Em 2016, houve a participação de apenas 31 IES com concluintes em cursos a distância. Dessas IES, 4 participaram apenas com concluintes EaD e tiveram conceitos que variaram entre 1,35 e 1,81 (Conceito Enade faixa=2). As 27 restantes participaram com alunos das duas modalidades. Esse contingente foi formado por 2 IES públicas e 25 privadas. Em ambas as públicas, o desempenho dos concluintes de cursos presenciais foi maior e, das 25 privadas, 16 cursos presenciais obtiveram conceitos maiores do que os cursos da mesma IES desenvolvidos a distância e, nos outros 9 , o desempenho $\mathrm{EaD}$ foi superior àquele dos concluintes a distância (Figura 3).

Finalmente, em 2017, um total de 127 IES participaram do exame com algum concluinte de curso EaD. Quatro delas com apenas concluintes nessa modalidade, 
todas privadas e com conceitos oscilando entre 1,10 e 2,26 (Enade faixa 2 a 3). Das outras 125, 57 eram públicas e 68 privadas. Ao ser feita a comparação entre a média dos conceitos dos cursos das duas modalidades para cada IES, verificou-se uma distribuição diferente entre os concluintes de escolas públicas e privadas, a exemplo do que já ocorrera nos anos anteriores: nas IES públicas, 51 instituições tiveram conceitos superiores para egressos de cursos presenciais e apenas 6 para egressos EaD. Nas IES privadas, os concluintes de 36 instituições tiveram melhor desempenho quando originários de cursos a distância e 32, de cursos presenciais (Figura 3).

Apesar desse comportamento global, resultados obtidos por Bielschowsky (2018b) mostram não haver diferenças significativas entre o desempenho dos egressos de cursos presenciais ou a distância das IES públicas do estado do Rio de Janeiro, que formam o Consórcio Cederj. $\mathrm{O}$ autor também chama a atenção para desempenhos menores nas IES privadas, especialmente naquelas em que há muitos egressos nos cursos $\mathrm{EaD}$.

Ao calcular a média ponderada dos conceitos obtidos pelas IES analisadas, respeitando os dois conjuntos referentes à natureza jurídica delas, pôde-se confirmar alguns comportamentos já observados quando da análise dos quartis de distribuição de alunos participantes do exame, destacando-se: a) os concluintes de cursos a distância têm um percentual de comparecimento aos exames menor do que dos concluintes de cursos presenciais; b) as médias ponderadas dos conceitos obtidos pelos cursos $\mathrm{EaD}$ são numericamente menores que aquelas dos cursos presenciais; c) a variação do desempenho dos concluintes de cursos presenciais é menor do que aquela dos cursos $\mathrm{EaD}$, que têm maiores desvios-padrão e, assim, coeficiente de variação (CV) e d) o ano de 2016 foi aquele que apresentou o menor número de instituições com $\mathrm{EaD}$ participantes, do mesmo modo que já havia sido registrado para o número de cursos (Tabela 7).

Além disso, o número de participantes originários de cursos EaD foi menor do que o dos cursos presenciais nos 3 anos em que o exame foi estudado, com 176.572 concluintes EaD e 245.664 nos presenciais, mas representou $42 \%$ do contingente total de concluintes, que é um valor muito acima do que representam os matriculados na modalidade a distância apurados pelo Censo da Educação Superior de 2017 (INEP, 2019). Destaca-se que, no caso das IES privadas em 2017, houve mais participantes concluintes EaD do que presenciais (Tabela 7).

Como a média dos conceitos abrange distribuições normais, foram feitos os correspondentes testes $\mathrm{T}$ para contraste entre 2 médias, utilizando-se valor de probabilidade de $5 \%(\mathrm{p}=0,05)$, ou seja: a possibilidade de a análise retratar efetivamente a realidade é de $95 \%$. Os resultados mostraram que, nas IES públicas, 


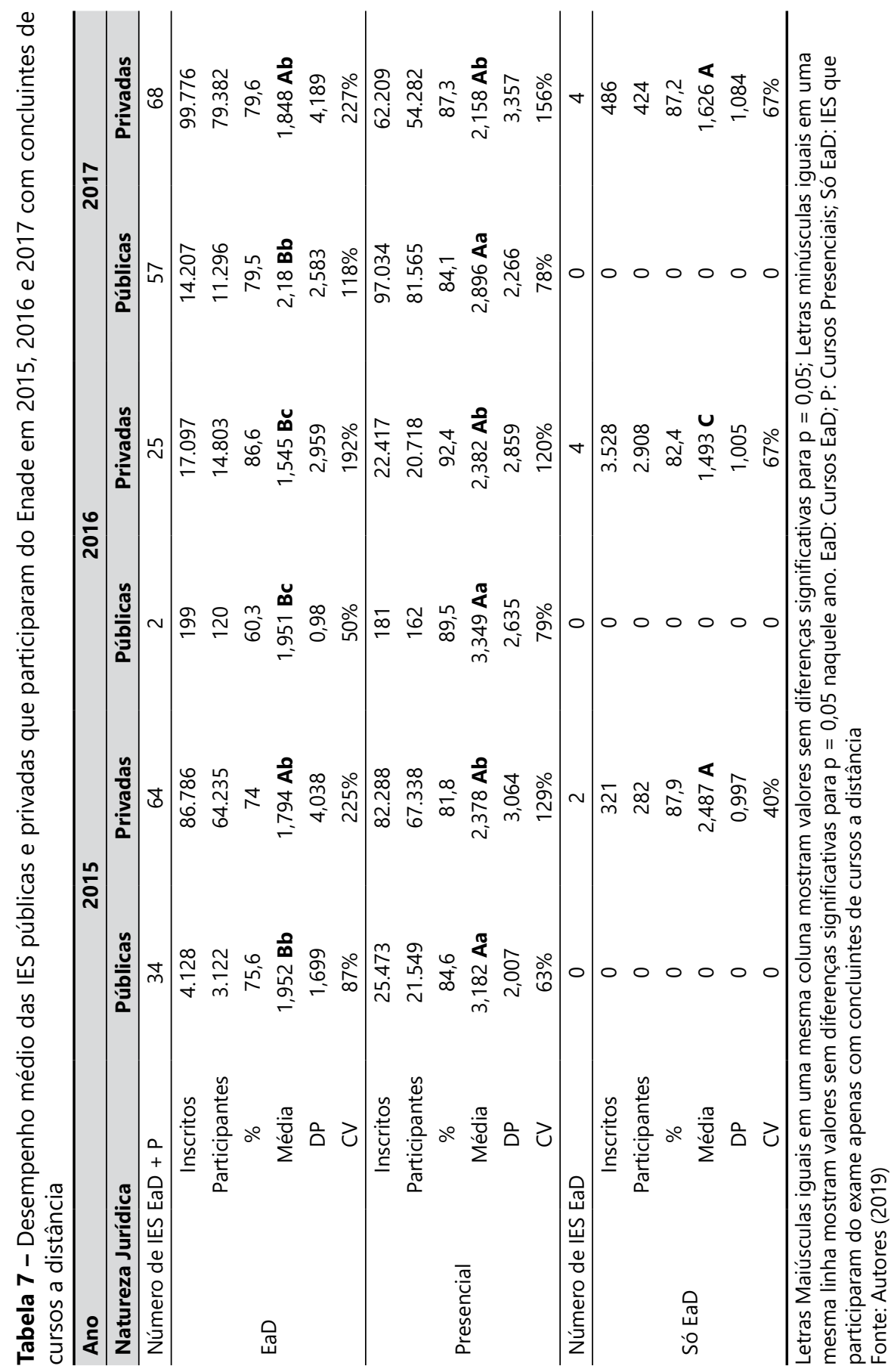


em todos os exames, o desempenho médio dos estudantes foi maior nos cursos presenciais com relação aos cursos a distância. Para as IES privadas, apesar dos conceitos apresentarem-se numericamente menores, não houve diferença significativa em 2015 e em 2017; em 2016, apresentaram-se valores menores $(\mathrm{p}=0,05)$ mas, aumentando-se o rigor da análise para uma significância de 96\% ou mais, essa diferença já não pode ser considerada significativa, confirmando a tendência já observada na Figura 3. Comportamento semelhante foi obtido com as instituições privadas que tiveram apenas participantes de cursos $\mathrm{EaD}$ (Tabela 7).

Quando se comparam os conceitos obtidos para cursos desenvolvidos a distância, em IES públicas e privadas, não se pode afirmar que haja diferenças significativas. Entretanto, para os cursos presenciais, em todos os exames analisados, os resultados foram diferentes $(\mathrm{p}=0,05)$ e sempre com maiores valores para as IES públicas em relação àquelas de natureza jurídica privada (Tabela 7).

Os resultados obtidos, de forma geral, para os cursos presenciais e a distância no presente trabalho confirmam aqueles obtidos por Caetano et al. (2015) para o curso de ciências contábeis no Enade de 2009, que também analisaram outras variáveis como a organização acadêmica e a natureza jurídica, para ingressantes e para concluintes, e aqueles obtidos por Bielschowsky com relação ao tamanho de turmas e ao desempenho no Exame (2018a, 2018b).

Desse modo, as análises realizadas nas IES públicas e privadas trouxeram novas características, com comportamentos nitidamente diferentes, conforme mostrado na Figura 3 e confirmados pelos resultados mostrados na Tabela 7: o conceito médio obtido pelas IES públicas, tanto pelos concluintes de cursos $\mathrm{EaD}$ quanto presenciais foi numericamente maior, com variabilidade menor em todos os casos analisados.

Os conceitos Enade faixa, em geral, refletiram essa diferença e foram, 3 para as IES públicas $\mathrm{EaD}$ e 2 para as privadas, a despeito de não haver diferença se comparado ao conceito Enade contínuo; nos cursos presenciais, essa tendência confirmou-se com conceito 4 para as IES públicas em 2015 e em 2016 e conceito 3 para todas as demais situações; a diferença entre o desempenho dos concluintes de cursos presenciais e a distância é maior nas IES públicas e distribuído de forma mais equitativa nas IES privadas; finalmente, o percentual de participantes no exame parece não ter relação com a natureza jurídica das IES, uma vez que houve situações em que as IES privadas tiveram maior percentual e casos em que ocorreu o oposto.

Como o Ensino Superior a distância é recente no panorama educacional brasileiro, é necessário que se tenha um cuidado especial no processo de aprendizagem dos 
estudantes dessa modalidade, mais do que apenas o seu desempenho no Enade, que, conforme todas as críticas, é uma sinalização de que o processo merece aprimoramentos. Alguns estudos apontam que um maior envolvimento dos estudantes com seu polo de apoio presencial tende a melhorar a sua aprendizagem (MACHADO, 2014) e a sensação de pertencimento também tem sido apontada como um fator importante no processo (LAGUARDIA; PORTELA, 2009). Além disso, o uso de avaliações formativas ao longo do desenvolvimento dos cursos pode representar um avanço importante para o entendimento, a análise e a melhoria do processo de Ensino-aprendizagem como um todo (PIVA JUNIOR.; CORTELAZZO, 2018), aí incluídos também os cursos presenciais.

\section{Considerações finais}

Apesar de o trabalho mostrar situações em que os valores médios são numericamente diferentes, o fato de haver uma variabilidade grande entre as médias denota que se trata de indicativo ou tendência, mas que não pode ser aferida estatisticamente uma diferença significativa entre os valores apresentados quando se compara à totalidade de cursos. Entretanto, quando foram consideradas apenas as IES que ofereciam cursos nas duas modalidades, foi possível uma análise estatística, confirmando comportamento diferenciado entre os conceitos Enade contínuo obtido, especialmente quando são agrupadas instituições de mesma natureza jurídica, pública ou privada.

A edição de novos exames poderá, em série histórica, confirmar as tendências e as diferenças observadas no ciclo avaliativo mostrado no presente trabalho.

Merecem destaque algumas considerações sobre as tendências e as diferenças detectadas:

a) Os concluintes oriundos de cursos $\mathrm{EaD}$ tendem a ter um percentual menor de participação nos exames quando comparados aos concluintes de cursos presenciais;

b) Os valores médios dos conceitos, realizada a devida ponderação em função do número de participantes, são, em geral, maiores para os cursos presenciais quando distribuídos todos os resultados dos cursos participantes dos exames;

c) A variabilidade de resultados é numericamente maior para os cursos $\mathrm{EaD}$ quando comparada aos cursos presenciais;

d) As turmas de concluintes com tamanho mais próximo à mediana $\left(2^{\circ}\right.$ e $3^{\circ}$ quartis) têm menor variabilidade quando comparadas àquelas muito pequenas 
( $1^{\circ}$ quartil) ou grandes ( $4^{\circ}$ quartil, especialmente naquelas IES com turmas de tamanho classificado como pontos desgarrados, ou $4^{\circ}$ quartil B);

e) Há uma tendência à diminuição de desempenho dos alunos de IES que formam uma quantidade muito grande de alunos, especialmente em cursos $\mathrm{EaD}$;

f) Apesar de as médias dos conceitos de IES públicas ser numericamente maior do que de IES privadas para concluintes de cursos $\mathrm{EaD}$, elas não apresentam diferenças significativas $(\mathrm{p}=0,05)$;

g) Nos cursos presenciais, as médias dos estudantes concluintes de IES públicas foi maior $(\mathrm{p}=0,05)$ para todos os exames analisados;

h) Em uma mesma IES, em média, as notas dos concluintes de cursos a distância é menor do que daqueles de cursos presenciais, mas não difere nas IES privadas (quando $\mathrm{p}=0,01$ ) ou são menores na área da saúde (quando $\mathrm{p}=0,05$ ).

i) As diferenças detectadas são relativas a um único exame de um dado curso e IES e, por isso, devem ser tratadas com a devida precaução, que poderá ser confirmada, ou não, nas próximas edições do Enade;

j) As médias utilizadas para a análise estatística, com o uso de Enade contínuo, passaram a representar um valor estático de desempenho, independentemente do número de concluintes das diferentes IES. Assim, deve ser encarado com reserva também pelo fato de que um conceito 2,1 decorrente do desempenho contínuo de 10 mil estudantes, tem, obviamente, uma consistência muito maior do que um conceito 3,8 decorrente do desempenho contínuo de 5 concluintes, apesar de, em ambos os casos, ser retratada a média ponderada de todos os participantes para uma mesma e única IES.

Os resultados obtidos apontam para a necessidade de outros trabalhos para comprovação das tendências aqui apresentadas, com um aprofundamento das análises estatísticas, a comparação específica de cada curso da mesma IES nas duas modalidades e também no desempenho de concluintes do período noturno ou diurno e em diferentes polos de apoio presencial, além de serem ampliados os conceitos de análise do Exame. Tais aprofundamentos estão sendo realizados e serão motivo de novas reflexões sobre o desempenho dos estudantes concluintes de cursos desenvolvidos a distância ou presencialmente. 


\section{Performance of undergraduate students from traditional and distance learning courses in the Enade Exams in 2015, 2016 and 2017}

\section{Abstract}

In order to compare the performance of undergraduate students of traditional and distance learning (DL) courses in the National Exams for Student Performance (Enade) of 2015, 2016 and 2017, an exploratory analysis of the results of these exams was carried out, with the determination of the obtained concepts, and with a comparison of the institutions that offer traditional and distance learning. The results showed that students of DL courses, especially those with a large number of graduates, tend to present a lower average performance, with a greater variability. For the same school that offered DL and traditional courses, the results showed that public institutions have significantly higher performance in traditional courses whereas in private institutions these values have no differences. For DL courses, despite numerically higher values in public institutions, there was no significant difference between the results in relation to private institutions.

Keywords: Higher Education. Enade exam. Evaluation. Traditional Learning. Distance Learning.

\section{Desempeño de los estudiantes de cursos presenciales y a distancia en Enade en 2015, 2016 y 2017}

\section{Resumen}

Con el objetivo de comparar el desempeño de los egresados de cursos presenciales y de Educación a distancia (EaD) en los Exámenes Nacionales de Desempeño del Estudiante (Enade) de 2015, 2016 y 2017, se realizó un análisis exploratorio de los datos disponibles, verificando el desempeño de los estudiantes de todas las clases participantes y de egresados de instituciones que ofrecían cursos presenciales y a distancia. Los resultados mostraron que los estudiantes de cursos de educación a distancia, especialmente aquellos con un gran número de graduados, tienden a presentar un concepto Enade continuo numéricamente menor y promedios con mayor variabilidad. Para una institución que ofrece cursos EaD y presenciales, hubo una diferencia en los resultados debido a su naturaleza jurídica: las escuelas públicas tuvieron conceptos significativamente más altos en los cursos presenciales mientras que en las privadas esta diferencia no se observó o fue menos evidente. Para los cursos EaD, a pesar de valores numéricamente más altos en las instituciones públicas, no hubo diferencia significativa entre los resultados.

Palabras-clave: Educación Universitaria. Enade. Evaluación. Enseñanza Presencial. Educación a Distancia. 


\section{Referências}

BIELSCHOWSKY, C. E. Análise dos resultados do Exame Nacional de Desempenho de Estudantes (Enade) para educação a distância do ciclo 2015 a 2017. EaD em Foco, Rio de Janeiro, v. 8, n. 1, out. 2018b. https://doi.org/10.18264/eadf.v8i1.758

BIELSCHOWSKY, C. E. Qualidade na educação superior a distância no Brasil: onde estamos, para onde vamos? EaD em Foco, Rio de Janeiro, v. 8, n. 1, e709, mar. 2018a. https://doi.org/10.18264/eadf.v8i1.709

BITTENCOURT, D. N.; ROESLER, J.; DIAS, J. S. Avaliação externa de cursos de graduação a distância: análise dos indicadores do MEC. In: QUEZADA, M. M.; RAMA, C. (ed.). Los problemas de la evaluación de la educación a distancia en América Latina y el Caribe. Quito: Loja, 2015. Cap. 2, p. 17-45.

BRASIL. Decreto $n^{\circ} 5.622$, de 19 de dezembro de 2005. Regulamenta o art. 80 da Lei n ${ }^{\circ}$ 9394, de 20 de dezembro de 1996, que estabelece as diretrizes e bases da educação nacional. Diário Oficial da União, Brasília, DF, 20 dez. 2005.

BRASIL. Lei no 9.394, de 20 de dezembro de 1996. Estabelece as diretrizes e bases da educação nacional. Diário Oficial da União, Brasília, DF, 23 dez. 1996.

BRASIL. Lei n ${ }^{\circ} 10.861$, de 14 de abril de 2004. Institui o Sistema Nacional de Avaliação da Educação Superior -SINAES e dá outras providências. Diário Oficial da União, Brasília, DF, 15 abr. 2004.

BRASIL. Ministério da Educação. Portaria Normativa no 40, de 12 de dezembro de 2007. Institui o e-MEC, sistema eletrônico de fluxo de trabalho e gerenciamento de informações relativas aos processos de regulação, avaliação e supervisão da educação superior no sistema federal de educação, e o Cadastro e-MEC de Instituições e Cursos Superiores e consolida disposições sobre indicadores de qualidade, banco de avaliadores (Basis) e o Exame Nacional de Desempenho de Estudantes (ENADE) e outras disposições. Diário Oficial da União, Brasília, DF, 29 dez. 2010.

BRITO, M. R. F. O SINAES e o ENADE: da concepção à implantação. Avaliação: Revista da Avaliação da Educação Superior (Campinas), Sorocaba, v. 13, n. 3, p. 841-850, nov. 2008. https://doi.org/10.1590/S1414-40772008000300014 
BRITO, T. F. Corpo docente: fatores determinantes do desempenho discente no ENADE. Dissertação (Mestrado em Ciências Contábeis) - Universidade de São Paulo, São Paulo, 2015.

CAETANO, C.C.R. et al. Desempenho no ENADE em Ciências Contábeis: ensino a distância (EAD) versus presencial. Revista Universo Contábil, Blumenau, v.11, n.4, p. 147-165, out/dez. 2015.

DIAS SOBRINHO, J. Avaliação e transformações da Educação Superior brasileira (1995-2009): do Provão ao Sinaes. Avaliação: Revista da Avaliação da Educação Superior (Campinas), Sorocaba, v. 15, n. 1, p.195-224, mar. 2010. https://doi.org/10.1590/S1414-40772010000100011

INSTITUTO NACIONAL DE ESTUDOS E PESQUISAS EDUCACIONAIS ANÍSIO TEIXEIRA - INEP. Sinopses estatísticas da Educação Superior 2018. 2018. Disponível em: http://portal.inep.gov.br/sinopses-estatisticas-do-Enade. Acesso em: 30 out. 2018.

INSTITUTO NACIONAL DE ESTUDOS E PESQUISAS EDUCACIONAIS ANÍSIO TEIXEIRA - INEP. Censo da Educação Superior 2019. Disponível em: http://portal.inep.gov.br/censo-da-educacao-superior. Acesso em: 10 mar. 2019.

LAGUARDIA, J.; PORTELA, M. Evasão na educação a distância. ETD Educação Temática Digital, Campinas, v. 11, n. 1, p. 349-379, jul./dez. 2009.

LAPPONI, J. C. Estatística usando Excel. 4. ed. São Paulo: Campus, 2005.

MACHADO, E.A. Desempenho acadêmico e satisfação dos estudantes na modalidade EaD: um estudo comparativo entre concluintes dos cursos de Ciências Contábeis e Administração. Tese (Doutorado em Controladoria e Contabilidade: Contabilidade) - Faculdade de Economia, Administração e Contabilidade, Universidade de São Paulo, São Paulo, 2014.

OLIVEIRA, E. T.; PICONEZ, S. C. B. Avaliação da educação superior nas modalidades presencial e a distância: análises com base no Conceito Preliminar de Cursos (CPC). Avaliação: Revista da Avaliação da Educação Superior (Campinas), Sorocaba, v. 22, n. 3, p. 833-851, nov. 2017. https://doi.org/10.1590/s1414-40772017000300014

PIVA JUNIOR, D.; CORTELAZZO, A. L. Diminuição da evasão decorrente do uso de avaliações formativas em sistema informatizado de desenvolvimento das disciplinas. In: CONGRESSO CLABES, 8., 2018, Cidade do Panamá. Disponível em: https://revistas.utp.ac.pa/ index.php/clabes/article/view/1931. Acesso em: 25 out. 2020. 
RODRIGUES, B. C. O. et al. Determinantes do desempenho acadêmico dos alunos dos cursos de Ciências Contábeis no ensino à distância. Enfoque Reflexão Contábil, Maringá, v. 35, n. 2, p. 139-153, 2016. https://doi.org/10.4025/enfoque.v35i2.30105

TUKEY, J. W. Exploratory data analysis. Reading: Addison-Wesley, 1977.

\section{Informações sobre os autores}

Angelo Luiz Cortelazzo: Livre-Docente em Biologia Celular pela Universidade Estadual de Campinas. Professor do Instituto de Biologia da mesma Universidade. Contato: alcortelazzo@gmail.com

(iD) http://orcid.org/0000-0002-3496-1219

Cristina de Carvalho Ares Elisei: Doutora em Engenharia Mecânica pela Universidade Estadual Paulista/Guaratinguetá. Diretora. Docente da Faculdade de Tecnologia de Pindamonhangaba. Contato: cristina.elisei@fatec.sp.gov.br

(iD) http://orcid.org/0000-0003-1111-2828 